\title{
Dynamic changes of inflammation and apoptosis in cerebral ischemia-reperfusion injury in mice investigated by ferumoxytol-enhanced magnetic resonance imaging
}

\author{
LIHUA ZHUANG $^{1}$, YINGNAN KONG ${ }^{1}$, SHUOHUI YANG $^{1}$, FANG LU $^{1}$, \\ ZHIGANG GONG ${ }^{1}$, SONGHUA ZHAN ${ }^{1}$ and MENGXIAO LIU ${ }^{2}$ \\ ${ }^{1}$ Department of Radiology, Shuguang Hospital, Shanghai University of Traditional Chinese Medicine, \\ Shanghai 201203; ${ }^{2}$ MR Scientific Marketing, Siemens Healthcare, Shanghai 201318, P.R. China
}

Received July 19, 2019; Accepted March 13, 2020

DOI: $10.3892 / \mathrm{mmr} .2021 .11921$

\begin{abstract}
The inflammatory response and apoptosis are key factors in cerebral ischemia-reperfusion injury. The severity of the inflammatory reaction and apoptosis has an important impact on the prognosis of stroke. The ultrasmall superparamagnetic iron oxide particle has provided an effective magnetic resonance molecular imaging method for dynamic observation of the cell infiltration process in vivo. The aims of the present study were to investigate the inflammatory response of cerebral ischemia-reperfusion injury in mice using ferumoxytol-enhanced magnetic resonance imaging, and to observe the dynamic changes of inflammatory response and apoptosis. In the present study a C57BL/6n mouse cerebral ischemia-reperfusion model was established by blocking the right middle cerebral artery with an occluding suture. Subsequently, the mice were injected with ferumoxytol via the tail vein, and magnetic resonance scanning was performed at corresponding time points to observe the signal changes. Furthermore, blood samples were used to measure the level of serum inflammatory factors, and histological staining was performed to assess the number of iron-swallowing microglial cells and apoptotic cells. The present results suggested that there was no significant difference in the serum inflammatory factors tumor necrosis factor- $\alpha$ and interleukin $1 \beta$ between the
\end{abstract}

Correspondence to: Professor Songhua Zhan, Department of Radiology, Shuguang Hospital, Shanghai University of Traditional Chinese Medicine, 528 Zhangheng Road, Shanghai 201203, P.R. China

E-mail: zhansonghua@sina.com

Abbreviations: MCAO, middle cerebral artery occlusion; USPIO, ultrasmall superparamagnetic particles of iron oxide; TNF- $\alpha$, tumor necrosis factor- $\alpha$; IL-1 $\beta$, interleukin- $1 \beta$; IBA1, ionized calcium binding adapter molecule 1; T1WI, T1-weighted image; T2WI, T2-weighted image

Key words: cerebral ischemia-reperfusion, ferumoxytol, inflammatory reaction, apoptosis, magnetic resonance middle cerebral artery occlusion (MCAO) and MCAO + ferumoxytol groups injected with ferumoxytol and physiological saline. The lowest signal ratio in the negative enhancement region was decreased $24 \mathrm{~h}$ after reperfusion in mice injected with ferumoxytol. The proportion of iron-swallowing microglial cells and TUNEL-positive cells were the highest at $24 \mathrm{~h}$ after reperfusion, and decreased gradually at 48 and $72 \mathrm{~h}$ after reperfusion. Therefore, the present results indicated that ferumoxytol injection of $18 \mathrm{mg} \mathrm{Fe} / \mathrm{kg}$ does not affect the inflammatory response in the acute phase of cerebral ischemia and reperfusion. Ferumoxytol-enhanced magnetic resonance imaging can be used as an effective means to monitor the inflammatory response in the acute phase of cerebral ischemia-reperfusion injury. Furthermore, it was found that activation of the inflammatory response and apoptosis in the acute stage of cerebral ischemia-reperfusion injury is consistent.

\section{Introduction}

Ischemic stroke is a common disease that affects human health, with high morbidity, mortality and disability rates worldwide $(1,2)$. After cerebral ischemia, the blood supply is restored for a certain period of time. However, brain function cannot be restored, and cerebral ischemia causes serious neurological dysfunction. Furthermore, secondary injury plays a key role in the process of cerebral ischemia-reperfusion nerve function damage, and the inflammatory reaction after stroke is an important aspect of secondary injury (3).

Apoptosis is an active process of cell death that occurs under physiological or pathological conditions (4). During the first few minutes to several days after cerebral ischemia, increased cell apoptosis occurs in ischemic areas, especially in ischemic penumbra areas, which also constitutes an important part of cerebral ischemic damage (5).

The inflammatory reaction and apoptosis are key components in cerebral ischemia-reperfusion injury (5-7). The severity of the inflammatory reaction and apoptosis has an important impact on the prognosis of stroke $(5,8)$. Furthermore, inflammation is expected to become a target for treatment of ischemic stroke. Thus, understanding the temporal and spatial 
changes of the inflammatory response and apoptosis in cerebral ischemia-reperfusion injury is important to help treatment of cerebral ischemia-reperfusion injury (9). Magnetic resonance scanning is a non-invasive, free-from-radiation technique that can be used to display cerebral ischemic foci from multiple angles (10). A T1-weighted image (T1WI) is a magnetic resonance image weighted by longitudinal relaxation time $\mathrm{T} 1$; T1WI can highlight the difference of tissue $\mathrm{T} 1$ relaxation (longitudinal relaxation). Moreover, a T2-weighted image (T2WI) is a magnetic resonance image weighted by transverse relaxation (spin-spin relaxation) time T2; T2WI can highlight the difference of tissue $\mathrm{T} 2$ relaxation (transverse relaxation). Furthermore, ischemic brain tissue shows low signals on T1WI, and a high signal on T2WI.

The ultrasmall superparamagnetic iron oxide particle (USPIO) is a new blood pool contrast agent, and an effective MRI molecular imaging method for dynamic observation of the cell infiltration process in vivo $(11,12)$. USPIO MRI can detect macrophages and inflammatory reactions in vivo, and has been used in the research of various diseases, such as stroke, prostate cancer and experimental autoimmune encephalomyelitis (13-18). USPIO particles can be phagocytized by macrophages, and thus can be used for imaging inflammatory reactions after cerebral ischemia (19). After cerebral ischemia, microglia, which exist in brain tissue and are the macrophages of the brain, are activated in large numbers, and these activated microglia can engulf specific paramagnetic USPIOs (20). The superparamagnetism of iron oxide nanoparticles means these particles exhibit high transverse relaxivity, and are thus used to produce signal loss in T2-weighted images (21). However, some particles exhibit significant longitudinal relaxivity and can produce hyperintensity in T1-weighted images under certain conditions (22).

Therefore, the present study used ferumoxytol to enhance MRIs to observe the inflammatory response in the acute stage of cerebral ischemia-reperfusion injury. The present study also investigated the dynamic changes of the inflammatory response and apoptosis after cerebral ischemia-reperfusion injury.

\section{Materials and methods}

Experimental animals. All experiments and procedures were approved by the Animal Ethics Committee of Shanghai University of Traditional Chinese Medicine (registration no. SZY201712006). In total, 54 wild-type, specific-pathogen free male C57BL/6n mice (age, 8-10 weeks; weight, 20-25 g) were purchased from Vital River Laboratory Animal Technology Co., Ltd. [license nos. SCXK (Beijing) 2016-0006 and SCXK (Zhejiang) 2018-0001]. Mice were reared in the Animal Experimental Centre of Shanghai University of Traditional Chinese Medicine, Animals were housed in a temperature $\left(22 \pm 2^{\circ} \mathrm{C}\right)$, humidity $(55 \pm 10 \%)$ and $12 \mathrm{~h} \mathrm{light} /$ dark cycle-controlled environment and given ad libitum access to food and water. The environmental facility license no. was SYXK (Shanghai): 2014-0008.

Experimental design. The 54 mice used in the study were divided into the sham-operation group (sham group), middle cerebral artery occlusion (MCAO) and MCAO + ferumoxytol groups ( $n=18$ mice in each group) according to their body weight. Each group was further divided into 24, 48 and $72 \mathrm{~h}$ subgroups, with 6 mice in each group. In the sham group, the common carotid artery, external carotid artery and internal carotid artery were separated; the specific separation steps were as the same as with the MCAO group, without the insertion of an occluding suture, and the specific separation steps are described in detail in the following paragraph. In the MCAO and MCAO + ferumoxytol groups, the right middle cerebral artery was blocked using a modified Longa suture method (23) to establish a cerebral ischemia-reperfusion model. Subsequently, mice in the sham and MCAO + ferumoxytol groups were injected with ferumoxytol (trade name, Feraheme; $1 \mathrm{mg} / \mathrm{ml}$; purchased from Canada by Shanghai So-Fe Biomedicine Technology Co., Ltd.; injection dose, $18 \mathrm{mg} \mathrm{Fe} / \mathrm{kg}$ ) via the tail vein after successful modelling. Mice in the MCAO group were injected through the tail vein with $0.9 \% \mathrm{NaCl}$ solution of equal volume after model establishment. The vital signs monitored after the operation included the body temperature and activity of the mice. The average time between suturing the animals and stabilizing the vital signs was 30-120 min; therefore, the injection was started $\sim 2 \mathrm{~h}$ after operation. During this time period ( $2 \mathrm{~h}$ after the surgery) the body temperature of the mouse was stable, and when this returned to normal, and the mice started eating and drinking; the injection dose was $0.02 \mathrm{ml}$ USPIO solution $/ \mathrm{g}$ mice. The mice were first scanned using MRI at the specified time, and then $0.5-1 \mathrm{ml}$ blood was collected by retroorbital exsanguination for the detection of serum inflammatory factors. The mice were sacrificed immediately after retroorbital exsanguination by cervical dislocation ( $n=6 /$ time point) at three-time points, and the brain tissues were taken for histological examination. During the experiment, the number of dead mice and the cause of death was recorded, and the mice in which MCAO was not established, which was observed in the T2-weighted images of the MRI, were removed. The model was subsequently re-established to supplement the sample size of the corresponding group. Fig. 1 shows the experimental design in further detail.

Improved method for establishing the cerebral ischemia model. All mice drank freely and were fasted for $12 \mathrm{~h}$ prior to the operation to prevent postoperative intestinal obstruction. The preparation method of cerebral ischemia-reperfusion in MCAO and MCAO + ferumoxytol groups were as described below. Mice were anaesthetized by intraperitoneal injection (1\% sodium pentobarbital, $35-40 \mathrm{mg} / \mathrm{kg}$ (Sinopharm Chemical Reagent Co., Ltd.), and tweezers were used to gently pinch the toes of the mouse. If the mouse did not have any reaction after pinching, it was considered to have entered a deep state of anesthesia. The skin was sterilized using an alcohol cotton ball after the mice were fixed in the supine position. The skin in the middle of neck was cut 1.0-1.5 cm using ophthalmology scissors. The subcutaneous tissues and glands were separated with ophthalmologic tweezers until the carotid sheath was exposed, to separate the right common carotid artery and the external carotid artery. Then, the proximal end of the common carotid artery and the external carotid artery were ligated. The occluding suture (diameter, $0.14 \pm 0.02 \mathrm{~mm}$; Beijing Cinotech Co., Ltd.) was placed into the $27 \mathrm{G}$ syringe 


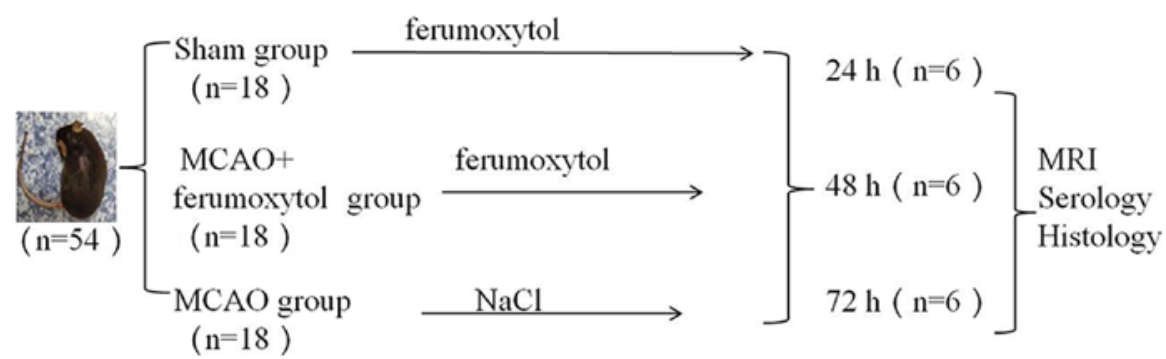

Figure 1. Experimental design. In total, 54 mice were randomly divided into sham, MCAO and MCAO + ferumoxytol groups according to their body weight. Each group was further divided into 24-, 48- and 72-h subgroups, with six mice in each group. Mice in the sham and MCAO + ferumoxytol groups were injected with $18 \mathrm{mg} \mathrm{Fe} / \mathrm{kg}$ ferumoxytol via the tail vein after successful modeling. Mice in the MCAO group were injected with $0.9 \%$ NaCl solution of equal volume after modelling. All mice underwent MRI at the corresponding time points, and then blood was collected for the detection of serum inflammatory factors. Mice were euthanized after retroorbital exsanguination, and the brains were removed for serological and histological studies. MCAO, middle cerebral artery occlusion.

needle (outer diameter, $0.4 \mathrm{~mm}$; needle length, $13 \mathrm{~mm}$ ), and the needle was inserted into the common carotid artery; the occluding suture was pushed from the tail of the needle, and the common carotid artery and its internal occluding suture were clamped with tweezers. The needle was subsequently withdrawn, and the occluding suture continued to be inserted into the internal carotid artery; the insertion process was stopped when resistance was encountered. At this point, the head end of the occluding suture was $\sim 1 \mathrm{~cm}$ from the bifurcation of the common carotid artery, and the beginning of the middle cerebral artery was blocked. The occluding suture and the common carotid artery were fixed together with a thin surgical suture, and the incision was sterilized and sewn up. After $30 \mathrm{~min}$, the nylon thread was withdrawn back to the bifurcation of the common carotid artery to cause reperfusion. The room temperature was kept at $\sim 25^{\circ} \mathrm{C}$ during and after the operation. The mice were irradiated with an incandescent lamp to keep the rectal temperature at $37.0 \pm 0.5^{\circ} \mathrm{C}$ after the operation. The mice were housed in a single cage and the neurological function score of each mouse was recorded using the Longa 5 grade method (24): i) 0, no obvious symptoms of neurologically defective function; ii) 1, on lifting the tail vertically, the opposite front paws could not be extended; iii) 2 , the mouse turned to the hemiplegic side when walking; iv) 3 , when walking, the body fell to the hemiplegic side; v) 4, the mouse could not walk spontaneously, and there was loss of consciousness; and vi) 5, death. Mice with a score of 1-3 were included in the experiment, and mice with a score of 0,4 or 5 , or those that died before the observation time point, were excluded. The health status of mice was observed every $4 \mathrm{~h}$; if mice were unable to eat, nutritional support was given by intraperitoneal injection of 0.2-0.5 ml physiological saline, according to their physical condition. If mice died before the MRI scan or before the serum samples were collected, mice of the same weight were randomly added to the group to ensure the same sample number of experimental animals in each subgroup. Neurological function of mice was also evaluated prior to MRI.

MRI acquisition and processing. All scans were performed on a Siemens Skyra3.0T machine with an 8-channel transverse coil for small animals (cat. no. 5000049101/001006; Shanghai Chenguang Medical Technology Co., Ltd.). The mice were anaesthetized by intraperitoneal injection (1\% pentobarbital sodium, 35-40 mg/kg; Sinopharm Chemical Reagent Co., Ltd.). The mice were fixed at the center of the coil in a prone position, and fast spin echo sequence scanning $(25,26)$ was performed. The sequence and specific parameters of MRI are shown in Table I. After MRI, the changes of MRI signals in the mouse brain tissues were observed, and a clinician with 5 years' clinical experience independently measured the signal values of the right negative enhancement region and the left corresponding region on T2WI images. The signal values of the left and right sides in the same region as the MCAO group were measured in the sham operation group. Calculations were performed as follows: The signal ratio of the sham operation group in $\mathrm{T} 2 \mathrm{WI}=$ right signal value/left signal value. The signal ratio of the $\mathrm{MCAO}+$ ferumoxytol group in $\mathrm{T} 2 \mathrm{WI}=$ right negative enhancement region signal value/left corresponding region signal value.

Serological tests. After the MRI scan, the mice were still anesthetized and the skin was disinfected around the orbit. Then, blood samples were collected by retroorbital exsanguination, and samples were centrifuged at $5 \mathrm{x}$ g for 15-20 min after standing for $30 \mathrm{~min}$. The upper serum was collected, and the serum levels of interleukin-1 $\beta$ (IL-1 $\beta$ ) and tumor necrosis factor- $\alpha$ (TNF- $\alpha$ ) were determined using their respective ELISA kits (cat. nos. 88-7013 and 88-7324; Thermo Fisher Scientific, Inc.).

Histological examination. After blood collection, the mice were euthanized by cervical dislocation. The brain tissue was removed, and the tissue samples were fixed at room temperature with $4 \%$ paraformaldehyde for $24 \mathrm{~h}$, prior to being embedded in paraffin. Brain tissues with negative enhancement corresponding to MRI coronal fracture images were sectioned (5- $\mu \mathrm{m}$ thick) for hematoxylin and eosin (HE) staining. Briefly, the tissue slides were placed in an oven at $60^{\circ} \mathrm{C}$ for $1 \mathrm{~h}$, deparaffinized with xylene 3 times for $20 \mathrm{~min}$ each at room temperature, rehydrated in a descending series of ethanol and washed in tap water. The sections were subsequently stained with hematoxylin (cat. no. H9627; Sigma-Aldrich; Merck $\mathrm{KGaA}$ ) for $10 \mathrm{~min}$ at room temperature and washed in running tap water for $5 \mathrm{~min}$. Then, the tissue slides were counterstained with eosin (cat. no. E4009; Sigma-Aldrich; Merck KGaA) for 


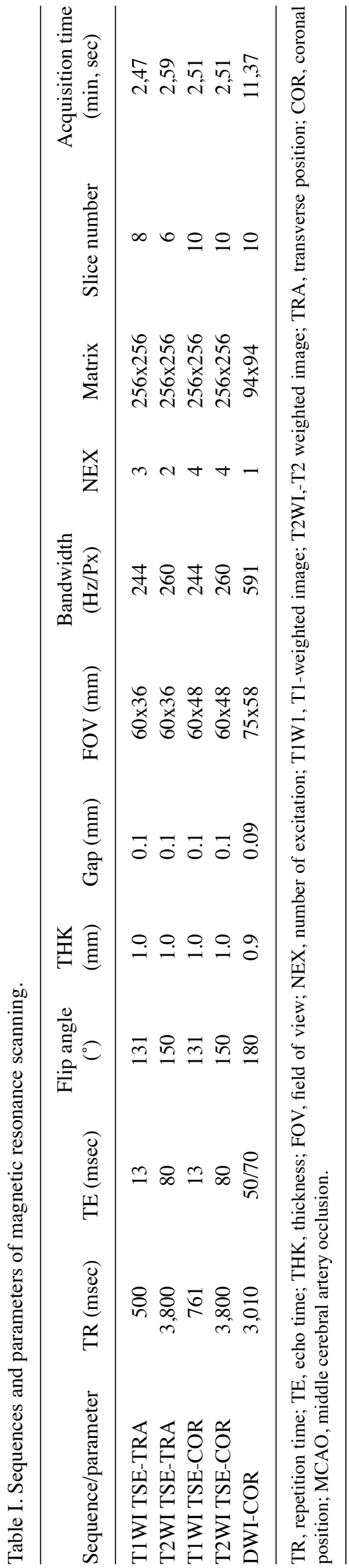

3 min at room temperature. The slides were dehydrated in 95 and $100 \%$ alcohol twice for 2 min each or until the excess eosin was removed. Slides were washed with xylene twice for 2 min each and mounted in Permount (Sinopharm Chemical Reagent Co., Ltd.).

Immunohistochemistry. IBA1 is a microglial cell/macrophage specific protein antibody (27-29). Brain tissue sections were prepared as described above for HE staining. The sections were deparaffinized with xylene three times for $20 \mathrm{~min}$ each at room temperature and rehydrated using a descending alcohol series, prior to undergoing heat-mediated antigen retrieval with boiled sodium citrate buffer ( $\mathrm{pH} \mathrm{6}$; cat. no. G1202; Wuhan Servicebio Technology Co., Ltd.) in a microwave oven for $20 \mathrm{~min}$. The sections were washed in PBS ( $\mathrm{pH} 7.4$; cat. no. G0002; Wuhan Servicebio Technology Co., Ltd.) 3 times for $5 \mathrm{~min}$ each time. The sections were blocked with 5\% rabbit serum (cat. no. G1209; Wuhan Servicebio Technology Co., Ltd.) for $30 \mathrm{~min}$ at room temperature before being incubated with the primary IBA1 antibody $(1: 2,000$; cat. no. ab178846; Abcam) overnight at $4^{\circ} \mathrm{C}$ to identify the microglial cells. Following the primary antibody incubation, a goat anti-rabbit horseradish-peroxidase secondary antibody (cat. no. K5007; Dako; Agilent Technologies, Inc.), without a dilution, was incubated with the sections for $30 \mathrm{~min}$ at room temperature. The slides were subsequently stained with 3,3'-diaminobenzidine and the phagocytized ferumoxytol was analyzed following the described method below.

Identification of phagocytized ferumoxytol. The phagocytized ferumoxytol was subsequently identified. The chemical formula of ferumoxytol is $\mathrm{Fe} 3 \mathrm{O} 4$, which is an inactive material, in which the Fe is trivalent iron (30). Potassium ferrocyanide solution can separate trivalent iron ions from proteins using dilute hydrochloric acid, and the trivalent iron is able to react with potassium ferrocyanide; this reaction produces an insoluble blue compound (31). In this experiment, after washing the sections that were stained with IBA1 antibody with running water, the Prussian blue iron stain kit (cat. no. GP1068; Wuhan Servicebio Technology Co., Ltd.) was used to identify phagocytized ferumoxytol in cells, according to the manufacturer's protocol. Briefly, a mixture of $2 \%$ potassium ferrocyanide and $2 \%$ hydrochloric acid was used to stain the trivalent iron ions for $1 \mathrm{~h}$ at room temperature, prior to washing with tap water. The sections were subsequently dehydrated with an ascending alcohol series, deparaffinized with xylene three times for 5 min each at room temperature and mounted in Permount (Sinopharm Chemical Reagent Co., Ltd.).

TUNEL staining. TUNEL was used to detect apoptotic cells using an apoptosis kit (in situ cell death detection kit; cat. no. 11684817910; Roche Applied Science). Firstly, paraffin-embedded sections of brain tissues were prepared according to the method in HE staining. The sections were deparaffinized with xylene twice for $5 \mathrm{~min}$ each at room temperature and rehydrated using a descending alcohol series, prior to being rinsed with PBS twice. Subsequently, $50 \mu 1$ TUNEL reaction mixture $(50 \mu 1 \mathrm{TdT}+450 \mu \mathrm{l}$ dUTP $)$ was incubated with the sections for $1 \mathrm{~h}$ at $37^{\circ} \mathrm{C}$ in the dark. After being washed with PBS 3 times, $100 \mu 1$ 3'3-Diaminobenzidine 
was added to the tissue and a light microscope (NIKON Eclipse 50i; Nikon Corporation) was used to observe the color change; the reaction was stopped when a yellow color appeared. The cell nuclei were counterstained with Harris hematoxylin (cat. no. H9627; Sigma-Aldrich; Merck KGaA) for $30 \mathrm{sec}$ at room temperature. The sections were dehydrated with an ascending series of alcohol, deparaffinized with xylene three times for 5 min each at room temperature and mounted as previously described.

Counting method. After all the samples were stained, all the sections (HE, IBA1, Prussian blue and TUNEL staining) were visualized using a digital pathology slide scanner (KFBIO KF-PRO-120; KFBIO Konfoong Bioinformation Tech Co., Ltd.) and analyzed using the digital slice reading software K-viewer version 1.1 (KFBIO Konfoong Bioinformation Tech Co., Ltd.). The HE staining focused on observing the presence of necrosis, edema and inflammatory cell infiltration in the brain tissue using x10, x200 and x400 magnification. IBA1 immunohistochemical staining and Prussian blue staining were mainly observed in the hippocampus at a magnification of $x 400$, whereas TUNEL staining was mainly observed in the cerebral cortex and brain tissue with a magnification of $\mathrm{x} 400$. Each animal had four non-repeated fields of view around the lesion. The high magnification images were taken from the low magnification of their panoramic images using K-viewer version 1.1 software. The immunohistochemical staining images were semi-quantitatively analyzed using ImageJ software version 1.8.0 (National Institutes of Health). and the specimens were scored according to the intensity of the dye color and the number of positive cells for IBA1 (32): The intensity of the dye color was graded as 0 (no color), 1 (light yellow), 2 (light brown), or 3 (brown), and the number of positive cells was graded as $0(<5 \%), 1(5-25 \%), 2(25-50 \%)$, $3(51-75 \%)$, or $4(>75 \%)$. The two grades were added together and the specimens were assigned to one of four levels: $0-1$ $(-), 2(+), 3-4(++)$ or $>5(+++)$; a score of $\geq 3$ was defined as IBA1-positive and when blue particles were observed in the cells, the cells were considered as Prussian blue staining positive. The number of cells was counted as the number of IBA1 + Prussian blue-positive and IBA1-positive cells, respectively; the ratio of these was taken as the positive cell percentage. The average value of the four graphs was taken as the positive cell percentage in the mouse. TUNEL staining was used to calculate the ratio of apoptotic cells/total cells in four non-repeating fields.

Statistical analysis. All statistical analyses were performed using SPSS 25.0 software (IBM Corp.). The neurological score of mice was described as the mode number. The MRI signal ratio, serum inflammatory factor level and activated microglia number were presented as the mean \pm SD. Serological comparisons were conducted using the one-way ANOVA; the least significant difference method was used for pairwise analysis. The Pearson correlation test was used to examine the correlation between T2WI minimum signal ratio and positive microglia ratio in the $\mathrm{MCAO}+$ ferumoxytol group. The graphs were created using GraphPad Prism version 7.04 (GraphPad Software, Inc.). $\mathrm{P}<0.05$ was considered to indicate a statistically significant difference.

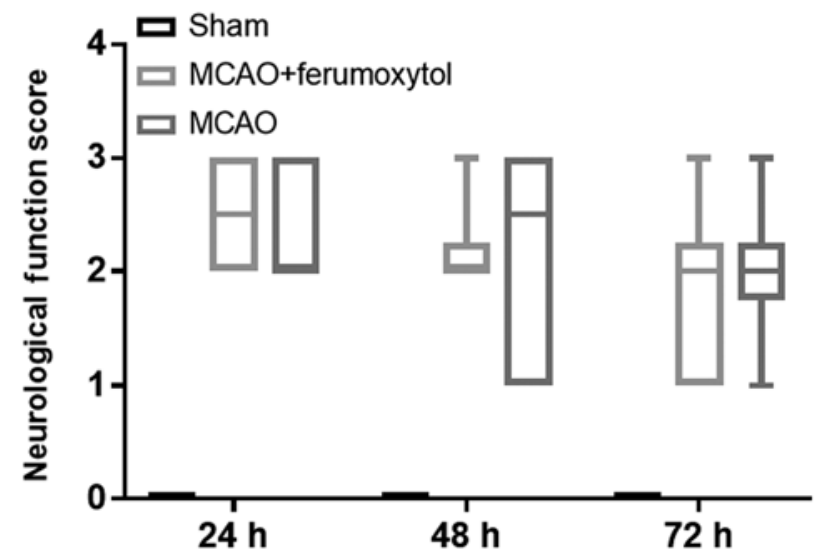

Figure 2. Neurological function score. Mice in the sham-operated group did not show neurological function deficits at different time points of reperfusion. Mice in the MCAO and MCAO + ferumoxytol groups had different degrees of neurological function deficit. MCAO, middle cerebral artery occlusion.

\section{Results}

During the modeling process, two mice died due to excessive bleeding during the modeling process, and two mice were excluded on the basis that no MCAO was observed in the T2-weighted images. The model was re-established in two additional mice to supplement the sample size of the corresponding group.

Neurological function score. The mice in the sham group did not show neurological function deficits at the different time points of reperfusion (all scores, 0 points). The mice in the MCAO and MCAO + Ferumoxytol groups had different degrees of neurological function defect. Moreover, the neurological function score was not normally distributed (Fig. 2); therefore, data were presented as the mode. The neurological function scores in the MCAO group were all 2 points at 24, 48 and $72 \mathrm{~h}$, and the neurological function scores in the $\mathrm{MCAO}+$ Ferumoxytol group were 3, 2 and 2 points at 24,48 and $72 \mathrm{~h}$, respectively (Fig. 2).

MRI signal changes in mice of each group. In the sham group, there were no significant signal changes in T1WI and T2WI at 24-72-h reperfusion. In the MCAO + ferumoxytol group, there were hyperintense areas in the right brain tissue on T2WI $\sim 24 \mathrm{~h}$ after reperfusion, with speckles and stripes of negative enhancement around this area. Furthermore, negative enhancement areas were observed on the infarct edge $48 \mathrm{~h}$ after reperfusion, and remained until $72 \mathrm{~h}$ after infarction. Moreover, these negative enhancement areas showed high signal on T1WI. In MCAO group, there were no obvious signal changes on T1WI, and large areas of hyperintense region were identified in the right brain tissue on T2WI, with no obvious negative enhancement surrounding the area (Fig. 3A). The signal ratio around the infarction in the MCAO + ferumoxytol group was the lowest at $24 \mathrm{~h}$ after reperfusion, and gradually increased over time. The signal ratio in the MCAO group was significantly higher compared with the sham and MCAO + ferumoxytol groups $(\mathrm{P}<0.05)$, and signal ratio in the MCAO group showed a slow downward 


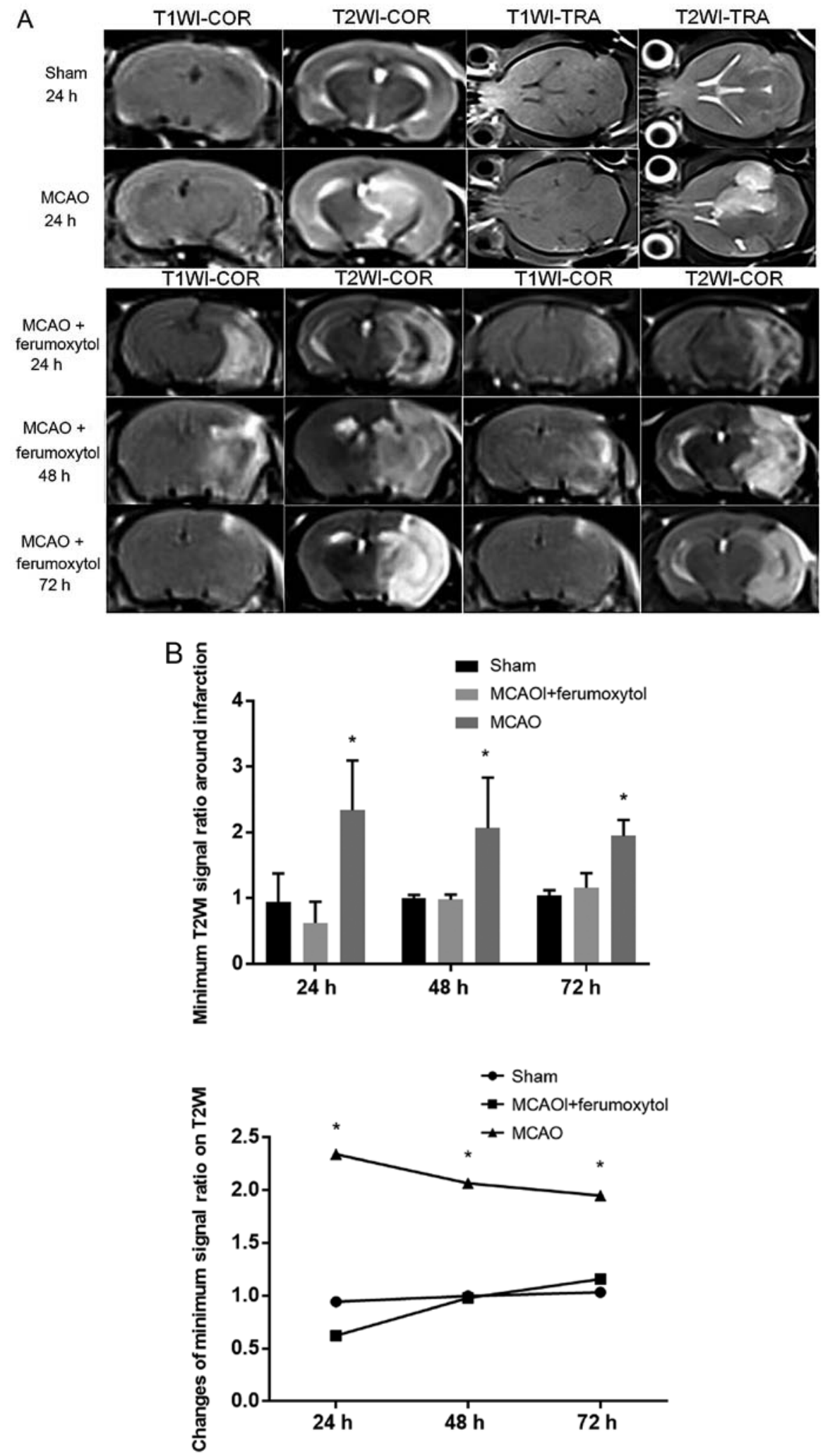

Figure 3. MRI signal changes. (A) MRI signal changes of mice in each group. No abnormal signal changes were found in T1WI and T2WI in the sham group. Hyperintense signal was seen in right-bnbrain tissue of T2WI in the MCAO group. MRI signal changes of mice in the MCAO + ferumoxytol group included high signal on T1WI, and patchy low signal on T2WI, in the infarct and its surroundings after $24 \mathrm{~h}$ perfusion. Slice high signal was identified on T1WI after $48 \mathrm{~h}$ reperfusion and low signal was seen on T2WI in corresponding area. Small patches of high signal were seen on T1WI and low signal was seen on $\mathrm{T} 2 \mathrm{WI}$ at $72 \mathrm{~h}$ after reperfusion in the MCAO + ferumoxytol group. (B) Signal ratio change of T2WI around infarction at 24, 48 and $72 \mathrm{~h}$ after reperfusion. ${ }^{*} \mathrm{P}<0.05$ vs. sham and MCAO + ferumoxytol. T1W1, T1-weighted image; T2WI, T2-weighted image; TRA, transverse position; COR, coronal position; MCAO, middle cerebral artery occlusion.

trend at 48 and $72 \mathrm{~h}$ after reperfusion. However, there was no significant change in the signal ratio of the right side and the left side of T2WI at each time point in the sham group, and the signal ratio was close to 1 (Fig. 3B). 


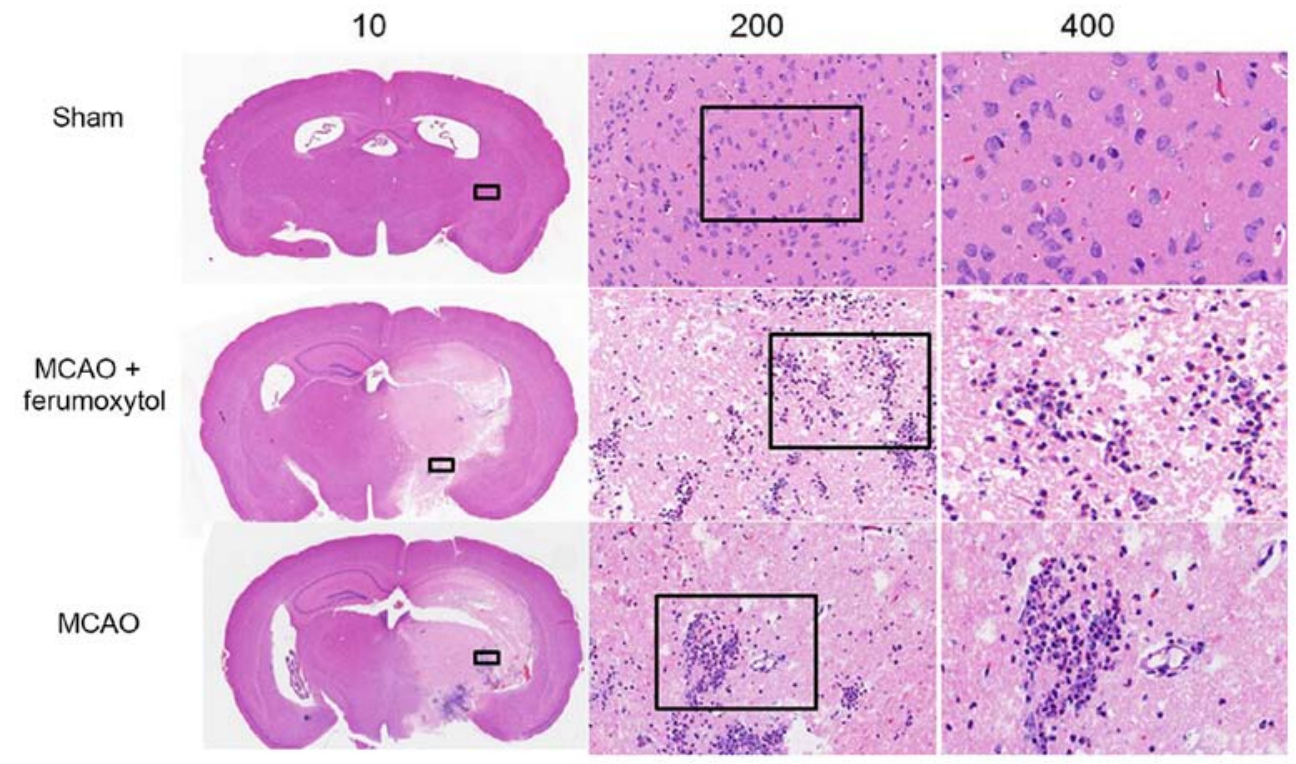

Figure 4. Histological examination. In the sham group, HE staining showed that the cells were arranged in an orderly fashion and no obvious edema was found. $\mathrm{HE}$ staining of MCAO and MCAO + ferumoxytol groups identified that brain tissue was seriously damaged, with a large number of necrotic cells, disordered cell arrangement, decreased number of neuron cells, obvious interstitial edema and a large number of inflammatory cells. Magnification, x10, x200 or x400. $\mathrm{HE}$, hematoxylin and eosin; MCAO, middle cerebral artery occlusion.
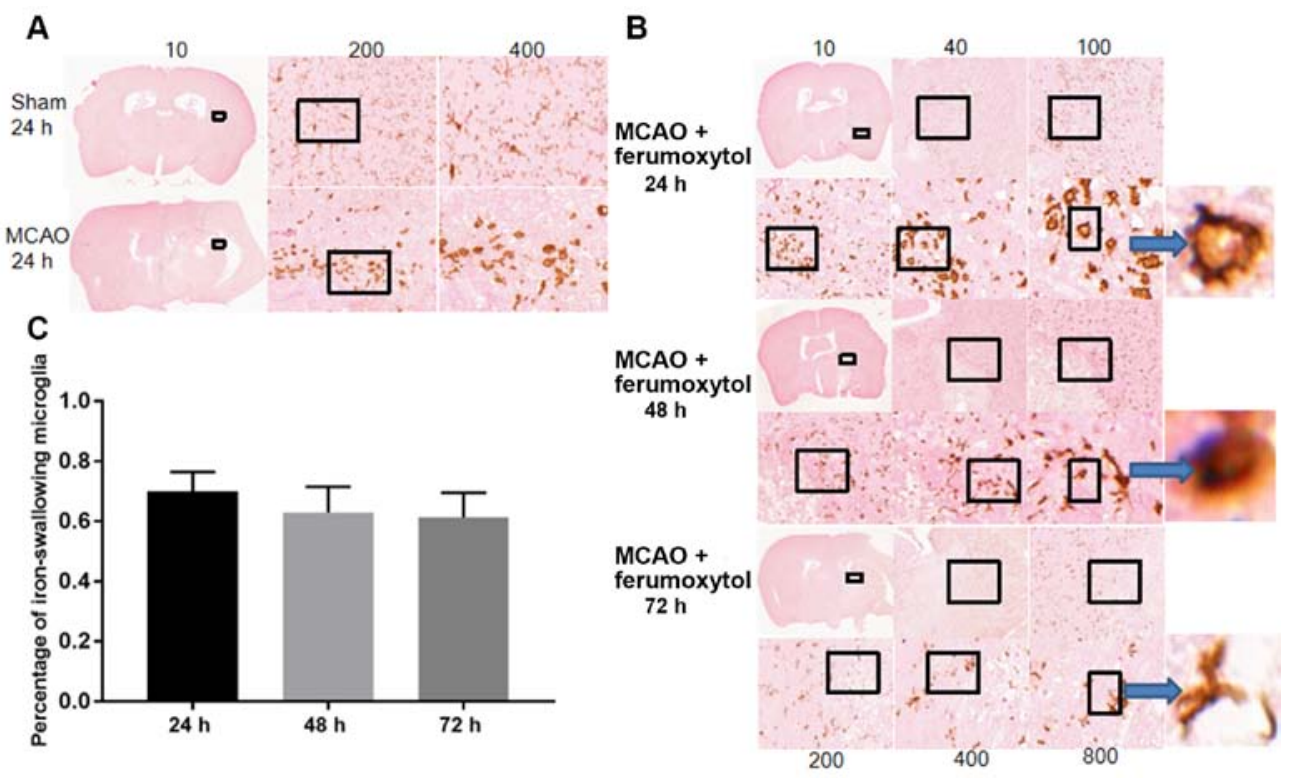

Figure 5. IBA1 + Prussian blue staining. Staining identified a small number of large, round or irregular activated microglia in the sham group, and a large number of branched inactivated microglia in MCAO group. (A) Results of IBA1 + Prussian blue staining in the MCAO + ferumoxytol group. Magnification, $\mathrm{x} 10, \mathrm{x} 200$ or $\mathrm{x} 400$. (B) Staining images and (C) quantification of the percentages of iron-engulfing microglia. Brown represents IBA1 positive expression and blue represents Prussian blue iron positive staining. Magnification, x10, x40, x100, x200, x400 or x800. IBA1, ionized calcium binding adapter molecule 1; MCAO, middle cerebral artery occlusion.

Histological examination. Mice in the sham group had a defined structure, neat cell arrangement, no obvious necrosis, compact intercellular space and very few inflammatory cells. However, in the MCAO and MCAO + ferumoxytol groups, the brain tissue was highly damaged with a large number of necrotic cells, disordered cell arrangement, interstitial edema and large numbers of inflammatory cells (Fig. 4). The IBA1 immunohistochemistry + Prussian blue staining results suggested that in the sham group there were a large number of stationary branched microglia with smaller cell bodies and radially tapering branches from the cell bodies, and also a small number of large, round or irregular activated microglia. It was demonstrated that in the MCAO and $\mathrm{MCAO}+$ ferumoxytol groups there were a large number of stationary branched microglia in the left cerebral parenchyma with smaller cell bodies and radially tapering branches from the cell bodies, and also a small number of large, round or irregular activated microglia. Moreover, a large number of activated microglia can be seen around the right cerebral parenchymal infarct in the MCAO group (Fig. 5A). In the 


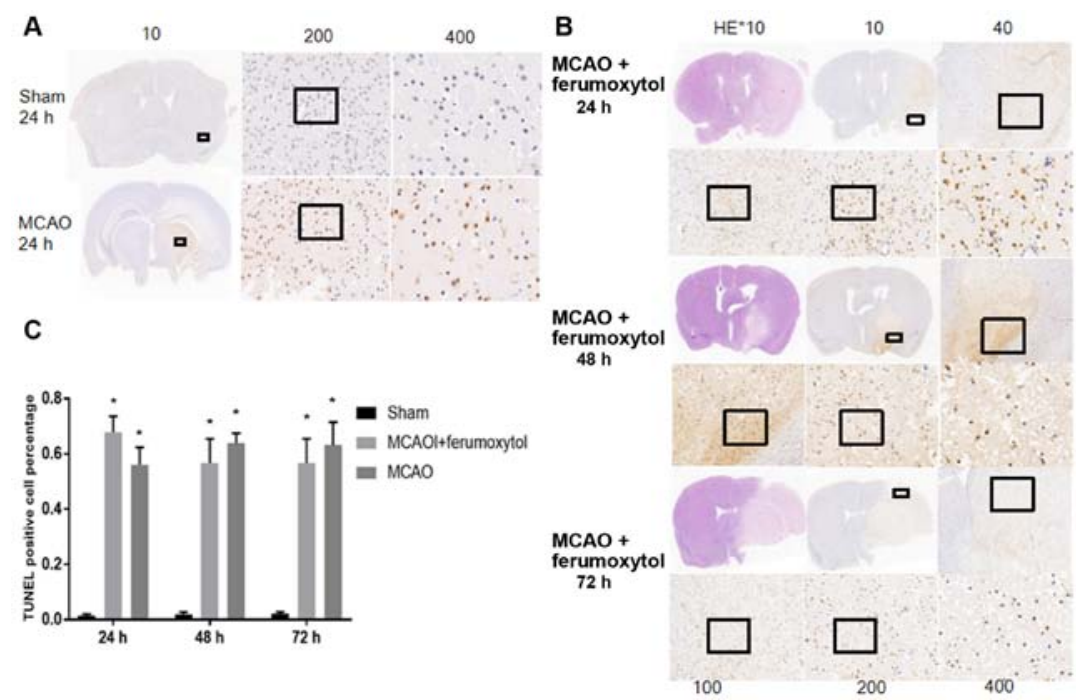

Figure 6. TUNEL staining showed no obvious apoptosis-positive cells in the sham-operation group and a large number of apoptotic-positive cells in the MCAO group. (A) TUNEL staining of the MCAO and sham groups. Magnification, $x 10, x 200$ or $x 400$. (B) TUNEL staining of the MCAO + ferumoxytol group. Magnification, x10, x40, x100, x200 or x400. (C) Quantification of the percentages of TUNEL positive cells. Brown yellow represents positive TUNEL expression. ${ }^{*} \mathrm{P}<0.05$ vs. sham group. MCAO, middle cerebral artery occlusion.

$\mathrm{MCAO}+$ ferumoxytol group, there were a large number of activated microglia at the infarct edge after reperfusion at $24 \mathrm{~h}$, and blue iron particles were found in the microglia. In addition, the number of activated microglia at the infarct edge decreased after reperfusion for 48 and $72 \mathrm{~h}$, a small number of activated positive cells were found in the infarct center, and a small number of blue iron particles were found in the intercellular substance (Fig. 5B and C).

TUNEL staining results indicated that there were no significant levels of positive apoptotic cells in the brain tissue of the sham group mice at various time points (Fig. 6A). The number of TUNEL cells in MCAO group and MCAO + ferumoxytol group was significantly higher compared with the sham group at the same time point $(\mathrm{P}<0.05)$. The aim of the present study was to investigate the level of the inflammatory reaction and apoptosis in the MCAO + ferumoxytol group, to see if ferumoxytol has influence on the inflammatory response. Therefore, only TUNEL images at $24 \mathrm{~h}$ reperfusion in the sham operation group and the MCAO group were shown (Fig. 6A). The present results suggested that a large number of positive apoptotic cells were identified in the infarct area and its surroundings in MCAO + ferumoxytol group $\sim 24 \mathrm{~h}$ after reperfusion, and the number of the apoptotic cells in the infarct area decreased over time (Fig. 6B and C).

Detection of the serum inflammatory factors TNF- $\alpha$ and $I L-1 \beta$. The inflammatory response is an important cause of secondary injury after stroke (33). Moreover, the release of various proinflammatory factors after cerebral ischemia aggravates ischemic injury (34). It was demonstrated that the serum levels of the inflammatory factors TNF- $\alpha$ and IL-1 $\beta$ in the $\mathrm{MCAO}$ and $\mathrm{MCAO}+$ ferumoxytol groups were significantly higher compared with the sham group at 24, 48 and $72 \mathrm{~h}$ after reperfusion $(\mathrm{P}<0.05$; Table II). To investigate the effect of $18 \mathrm{mg} \mathrm{Fe} / \mathrm{kg}$ ferumoxytol injection on the serum inflammatory factors in mice, the levels of the serum inflammatory factors TNF- $\alpha$ and IL- $1 \beta$ were detected in the MCAO and MCAO + ferumoxytol groups (Fig. 7). It was found that the serum levels of TNF- $\alpha$ and IL- $1 \beta$ were not significantly different between these two groups (Fig. 7).

Correlation between the MRI signal ratio and positive cell ratio. The present study tested the correlation between $\mathrm{T} 2 \mathrm{WI}$ signal ratio and IBA1 + Prussian blue positive cell ratio, at each time point in MCAO + ferumoxytol group. It was found that the correlation coefficients $\mathrm{R}$ at 24,48 and $72 \mathrm{~h}$ after reperfusion were $0.271,0.386$ and 0.410 , respectively, with no significant correlation (Table III).

\section{Discussion}

Cerebrovascular disease is a common, frequently occurring clinical disease with high mortality and disability rates. Using animal models to study cerebrovascular disease has become an important research method for investigating cerebral ischemia. The Longa modified thread embolism method is the most commonly used technique in cerebral ischemia research (35). This method has a constant ischemic site and can be used for reperfusion, simulating different states of permanent and transient focal cerebral ischemia in humans. Furthermore, this method allows for accurate control of ischemia and reperfusion time.

The present study aimed to improve some of the methodology of cerebral ischemia modeling in mice. During the modeling process, the present study used a suitable syringe needle to draw the occluding suture into the common carotid artery, which replaced the traditional ophthalmic scissors, which reduced intraoperative bleeding and greatly improved the success rate. The MCAO group and the MCAO + Ferumoxytol group had different degrees of neurological deficits after the model was established, which showed that the use of the improved thread plug method to create the model was beneficial. However, the present results suggested that the neural function scoring data did not conform to normal 

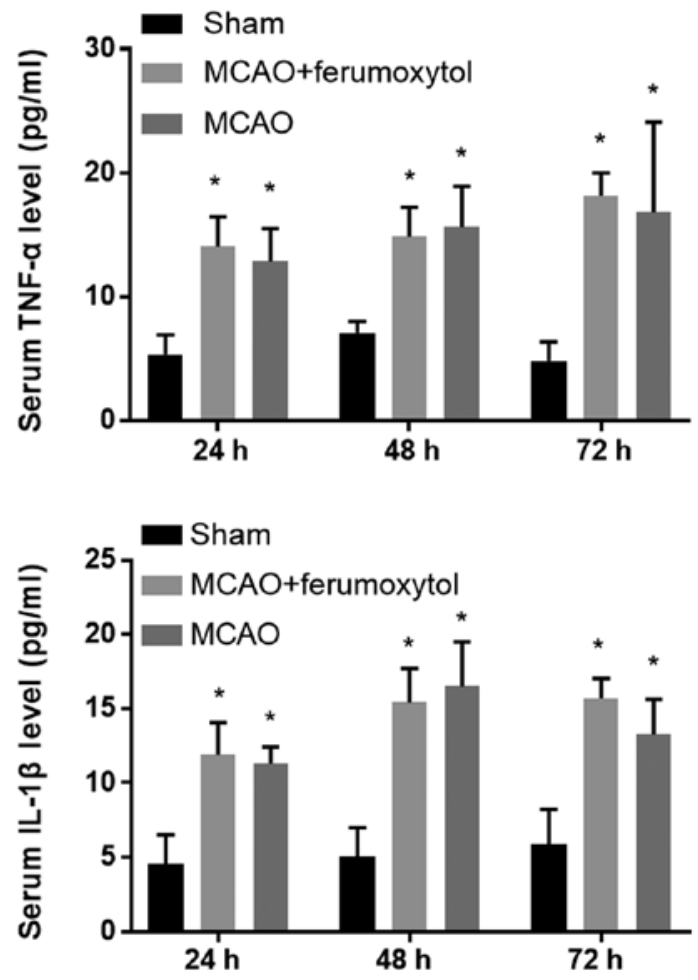

Figure 7. Serum levels of TNF- $\alpha$ and IL-1 $\beta$. At different time points after reperfusion, TNF- $\alpha$ and IL- $1 \beta$ in the MCAO and MCAO + ferumoxytol groups were higher compared with the sham group. There was no significant difference in TNF- $\alpha$ and IL- $1 \beta$ between the MCAO and MCAO + ferumoxytol groups. ${ }^{*} \mathrm{P}<0.05$ vs. sham group. TNF- $\alpha$, tumor necrosis factor- $\alpha$; IL-1 $\beta$, interleukin-1 $\beta$; MCAO, middle cerebral artery occlusion.

distribution, and the SD was large. The reason for this may be due to the shortcomings of Longa 5 grade scoring method, which is subjective. Furthermore, in our present study, the evaluation is not sufficiently comprehensive, and the score is not detailed to the required degree, which leads to poor sensitivity in terms of evaluating neurological deficits in mice.

In previous studies that investigated changes in cerebral ischemia, the animals were typically euthanized after establishment of the cerebral ischemia model, and then sections were obtained to observe the pathological changes; this procedure requires a large number of experimental animals $(24,36)$. Furthermore, non-invasive and dynamic monitoring of cerebral ischemia, and inflammatory injury in vivo, allows for continuous and dynamic observation in the same organism (37). MRI is a high-resolution technique for soft tissue, and further advantages are that there is no radiation damage and the method can be used repeatedly. Moreover, MRI is a multi-parameter, multi-sequence and multi-slice imaging technique, making it an important method for in vivo research (38).

USPIO is a new type of MRI negative contrast agent with several advantages, including being effective at the nano-scale, blood pooling, specific targeting, biocompatibility, longer blood half-life and no long-term toxicity $(12,39)$. USPIO is able to change the longitudinal and transverse relaxation time, and can also change the MRI signal (40). Therefore, the pathological changes involved in the inflammatory response can be detected in vivo using this imaging technology, and it has gained increasing attention for use as a mononuclear phagocyte system-specific MRI contrast agent. Currently, 
Table III. Correlation between the T2WI signal ratio and the IBA1 + Prussian blue positive cell ratio in the middle cerebral artery occlusion + ferumoxytol group.

\begin{tabular}{lccc}
\hline Parameter & $24 \mathrm{~h}$ after reperfusion & $48 \mathrm{~h}$ after reperfusion & $72 \mathrm{~h}$ after reperfusion \\
\hline T2WI signal ratio & $0.9432 \pm 0.4321$ & $0.9968 \pm 0.0507$ & $0.10326 \pm 0.8729$ \\
IBA1 + Prussian blue positive cell ratio & $0.6999 \pm 0.6043$ & $0.6295 \pm 0.8616$ & $0.6136 \pm 0.8152$ \\
Correlation coefficient, $r$ & 0.271 & 0.386 & 0.410 \\
\hline
\end{tabular}

T2WI, T2-weighted image; IBA1, ionized calcium binding adapter molecule 1.

USPIO has been used for cell tracing-related research, including autoimmune encephalomyelitis, atherosclerosis and other diseases $(18,41-44)$. For inflammatory diseases of the central nervous system, USPIO can be used as both a marker of cell infiltration and a marker of blood-brain barrier destruction, which is a new method for inflammatory imaging of the central nervous system $(45,46)$. Previous studies have used USPIO to investigate whether the inflammatory reaction has a correlation with cerebral infarction volume (47).

The component of USPIO selected in the present study was ferumoxytol, which is an USPIO approved by the Food and Drug Administration to treat iron deficiency anemia caused by chronic kidney disease in adults; the chemical formula of ferumoxytol is $\mathrm{Fe}_{3} \mathrm{O}_{4}(30,48)$. Ferumoxytol, as an ultrasmall, ultra-paramagnetic material, has become more commonly used for investigating central nervous system diseases, including post-stroke perfusion imaging or cell integration $(49,50)$. Previous studies have used USPIO to investigate the in vivo mechanisms of inflammatory response, but have not observed the dynamic changes of the inflammatory response and apoptosis in depth (51-53). The inflammatory response and apoptosis are the most important pathological changes after stroke. Thus, in the present study it was important to assess the dynamic changes of the inflammatory response and apoptosis. Previous studies have found that USPIO can play an anti-inflammatory and pro-inflammatory role, or have no effect on inflammation (54-57). However, in vitro studies revealed that the influence of USPIO on the inflammatory reaction is associated with particle size, different surface modifications, injection concentration and time (54-56,58). While Doyle et al (59) found that ferumoxytol did not affect the cerebral infarction volume and inflammatory response of mice, results that are inconsistent with the present study. There are a couple of major differences between the present study and that by Doyle et al (59): i) the injection concentration and injection time differed (i.e., in the previous study, $7 \mathrm{mg} / \mathrm{kg}$ ferumoxytol were injected $48 \mathrm{~h}$ after MCAO); and ii) the present study used C57BL/6n mice, whereas the previous study used BALB/CJ mice. Therefore, at present, there are no reliable data to show the effect of $18 \mathrm{mg} \mathrm{Fe} / \mathrm{kg}$ ferumoxytol on the inflammatory response following cerebral ischemia in C57BL/6n mice. If the volume of ferumoxytol used in the present study were to have intensified or alleviated the inflammatory reaction, it would not have been appropriate to have used this concentration to study the inflammatory reaction in itself. The present study used the MCAO + normal saline group as a control to compare the differences between the serum inflammatory factors TNF- $\alpha$ and IL-1 $\beta$ between experimental groups; this represents the most novel aspect of the present study.

The present results suggested that there were no significant differences in the serum levels of the inflammatory factors TNF- $\alpha$ and IL-1 $\beta$ comparing between the MCAO and $\mathrm{MCAO}+$ ferumoxytol groups at 24, 48 and $72 \mathrm{~h}$ after cerebral ischemia-reperfusion. Therefore, the present results indicated that $18 \mathrm{mg} \mathrm{Fe} / \mathrm{kg}$ ferumoxytol, which was used to assess the inflammatory reaction, does not affect the release of TNF- $\alpha$ and IL-1 $\beta$. Consequently, in the present study it was feasible to inject $18 \mathrm{mg} \mathrm{Fe} / \mathrm{kg}$ ferumoxytol to investigate in vivo the MRI of the inflammatory response after cerebral ischemia. A previous clinical study showed that USPIO-enhanced MRI may facilitate a more specific treatment of inflammation in patients with stroke (60). Microglia are macrophages in the brain that can react rapidly to changes in the brain microenvironment (20). Microglia are important imaging targets for studying the inflammatory response after stroke (61). The region where USPIO aggregation causes signal changes on magnetic resonance images represents the activated microglia aggregation region (62). While ferumoxytol has a long half-life in blood, its half-life is only $45 \mathrm{~min}$ in mice, and previous studies have shown that almost no ferumoxytol is present in cerebral vessels $24 \mathrm{~h}$ after injection (63). Moreover, another previous study demonstrated that the signal changes in MRI at the early stage are not caused by phagocytosis of iron particles by blood-derived macrophages (64). In addition, the inflammatory response after cerebral ischemia is a dynamic process (65). Following cerebral ischemia-reperfusion, the metabolic and vasoactive substances increase vascular permeability and vascular endothelial cells release adhesion factors (66). Furthermore, white blood cell aggregation-adhesion-exudation is initiated, with neutrophils arriving first, monocytes predominating $24 \mathrm{~h}$ later, and blood-derived macrophages infiltrating in large quantities 3 days after cerebral ischemia (66). Inflammatory cells in brain tissue within 24-72 $\mathrm{h}$ following cerebral ischemia-reperfusion are mainly inherent microglial cells in the brain (67). Therefore, MRI signal changes within 24-72 h after cerebral ischemia are mainly caused by activated phagocytosis of iron particles by microglia (64). However, the dynamic changes of microglial cells at 24-72 $\mathrm{h}$ after cerebral ischemia-reperfusion have yet to be fully elucidated. Therefore, the present study observed the activation of endogenous microglial cells during the 24-72 $\mathrm{h}$ period after cerebral ischemia-reperfusion, and compared changes in the MRI signals with brain histopathology. The present study used the lowest signal ratio of T2WI to reflect 
the degree of activation in microglial cells that engulfed ferumoxytol; the lower the ratio, the higher the degree of activation of the microglia.

Apoptosis is a relatively ordered, delayed energy-dependent cell death process. Following cerebral ischemia, due to the collateral circulation blood supply in the area surrounding the necrotic region, the degree of ischemia is lower compared with the central area, there is provision of a partial energy supply, and cell damage is relatively slight (68). Reperfusion injury can produce calcium ion imbalance, endoplasmic reticulum and mitochondrial dysfunction, and enhanced peroxidation, which leads to DNA damage (69). Moreover, a large degree of reperfusion injury can initiate cell apoptosis $(5,70)$.

The present results suggested that the negative enhancement areas of T2WI in the cerebral ischemic area are primarily concentrated around the infarction in the MCAO + ferumoxytol group. Immunohistochemical staining results showed a large number of activated microglia in these negative enhancement areas, with positive iron particles visible in the microglia. Furthermore, TUNEL staining results identified a large number of apoptotic cells in these areas, indicating that apoptosis and the activation of microglia occur consistently 24-72 $\mathrm{h}$ after cerebral ischemia-reperfusion. Moreover, the MRI T2WI-enhanced region signal ratio results suggested that the signal was lowest $24 \mathrm{~h}$ after reperfusion, and the degree of microglial cell activation and apoptosis were highest at this time point. Thus, the present results suggested that ferumoxytol-enhanced MRI may be used as an effective strategy to monitor the inflammatory response in the acute stage of cerebral ischemia-reperfusion injury. It was demonstrated that there is a peak in the inflammatory response at $24 \mathrm{~h}$ after cerebral ischemia-reperfusion, which was accompanied by a peak of apoptosis. Thus, the activation of the inflammatory response after cerebral ischemia-reperfusion injury is consistent with apoptosis.

However, there are several limitations to the present study. Firstly, the T2WI signal ratio was used to evaluate the level of iron consumed by cells, but SWI is the most sensitive and non-invasive method for iron quantification (71). However, the mouse brain tissue voxels used in the present study are small, and thus we failed to obtain satisfactory SWI images on 3T machines. In addition, the weak linear correlation is due to the fact that cells that internalize USPIO are primarily activated macrophages. However, there are other cell types involved, and parts of USPIO that are not engulfed reach the site directly via the damaged blood-brain barrier. In addition, previous studies have shown that USPIO in the cell stroma prove to be difficult to stain using Prussian blue (72): A technique that was used in the present study. Moreover, the T2WI scanning plane may not be identical to the IBA1 immunohistochemical iron counterstain section, and due to the heterogeneity of microglial cell distribution, the proportion of positive cells obtained in this plane cannot fully represent the overall situation of the lowest signal area. In addition, while no visible hemorrhage foci are found upon MRI scanning, HE detection showed that some mice had gastric hemorrhage. Therefore, these factors may explain why the lowest signal ratio in the subsequent MR T2WI and the positive cell ratio were not correlated.

Collectively, the present results suggested that ferumoxytol-enhanced MRI may reflect the activation of microglial cells in brain tissue $24-72 \mathrm{~h}$ after cerebral ischemia-reperfusion in vivo. Thus, the present results may provide a useful imaging method to observe the inflammatory response after cerebral ischemia. Moreover, the histological examination results indicated that the dynamic changes of microglial cell activation and apoptosis are highly consistent; therefore, further studies are required to investigate the pathological changes, diagnosis and treatment of cerebral ischemia.

\section{Acknowledgements}

The authors would like to thank Miss Liu Mengxiao, the Siemens Shanghai engineer of MR Scientific Marketing, Siemens Healthcare, for adjusting the magnetic resonance scanning parameters in this study, and Shanghai Runnerbio Technology Co., Ltd. for helping with the histological examination.

\section{Funding}

This research was supported by The General Program of China National Natural Science Foundation (grant no. 81573782).

\section{Availability of data and materials}

The datasets used and/or analyzed during the current study are available from the corresponding author on reasonable request.

\section{Authors' contributions}

SZ conceived and designed the experiments. LZ performed the experiments and was a major contributor in writing the manuscript. YK participated in establishing the model and analyzed the data. SY and FL analyzed the data and critically revised the manuscript. ZG and ML helped with the magnetic resonance sequence in the mice. SZ supervised all research and revised the manuscript. All authors read and approved the final manuscript.

\section{Ethics approval and consent to participate}

All experimental procedures were approved by the Animal Care and Use Committee of Shanghai University of Traditional Chinese Medicine (registration no. SZY201712006).

\section{Patient consent for publication}

Not applicable.

\section{Competing interests}

The authors declare that they have no competing interests.

\section{References}

1. Guzik A and Bushnell C: Stroke epidemiology and risk factor management. Continuum (Minneapolis, Minn.) 23: 15-39, 2017.

2. Wang Y, Cui L, Ji X, Dong Q, Zeng J, Wang Y, Zhou Y, Zhao X, Wang C, Liu L, et al: The China national stroke registry for patients with acute cerebrovascular events: Design, rationale, and baseline patient characteristics. Int J Stroke 6: 355-361, 2011. 
3. Duris K and Jurajda M: Evolutionary concept of inflammatory response and stroke. J Neurosci Res 98: 98-104, 2020.

4. Elmore S: Apoptosis: A review of programmed cell death. Toxicol Pathol 35: 495-516, 2007.

5. Radak D, Katsiki N, Resanovic I, Jovanovic A Sudar-Milovanovic E, Zafirovic S, Mousad SA and Isenovic ER: Apoptosis and acute brain ischemia in ischemic stroke. Curr Vasc Pharmacol 15: 115-122, 2017

6. Kim E and Cho S: Microglia and monocyte-derived macrophages in stroke. Neurotherapeutics 13: 702-718, 2016.

7. Jin R, Yang G and Li G: Inflammatory mechanisms in ischemic stroke: Role of inflammatory cells. J Leukoc Biol 87: 779-789, 2010

8. Duris K, Splichal Z and Jurajda M: The role of inflammatory response in stroke associated programmed cell death. Curr Neuropharmacol 16: 1365-1374, 2018

9. Chauveau F, Cho TH, Berthezene Y, Nighoghossian N and Wiart M: Imaging inflammation in stroke using magnetic resonance imaging. Int J Clin Pharmacol Ther 48: 718-728, 2010.

10. Antonucci MU and Yazdani M: A helpful tool in diagnosing stroke mimics: Arterial spin labeled perfusion magnetic resonanceimaging. J Emerg Med: Mar 18, 2020 (Epub ahead of print).

11. Rausch M, Sauter A, Fröhlich J, Neubacher U, Radü EW and Rudin M: Dynamic patterns of USPIO enhancement canbe observed in macrophages after ischemic braindamage. Magn Reson Med 46: 1018-1022, 2001

12. Weissleder R, Stark DD, Engelstad BL, Bacon BR, Compton CC, White DL, Jacobs P and Lewis J: Superparamagnetic iron oxide: Pharmacokinetics and toxicity. AJR Am J Roentgenol 152: 167-173, 1989.

13. Hedgire S, Krebill C, Wojtkiewicz GR, Oliveira I, Ghoshhajra BB Hoffmann U and Harisinghani MG: Ultrasmall superparamagnetic iron oxide nanoparticle uptake as noninvasive marker of aortic wall inflammation on MRI: Proof of concept study. Br J Radiol 91: 20180461, 2018.

14. Duan X, Wang Y, Zhang F, Lu L, Cao M, Lin B, Zhang X, Mao J, Shuai $X$ and Shen J: Superparamagnetic Iron Oxide-loaded cationic polymersomes for cellular MR imaging of therapeutic stem cells in stroke. J Biomed Nanotechnol 12: 2112-2124, 2016.

15. Debats OA, Fortuin AS, Meijer HJ, Hambrock T, Litjens GJ, Barentsz JO and Huisman HJ: Intranodal signal suppression in pelvic MR lymphography of prostate cancer patients: A quantitative comparison of ferumoxtran-10 and ferumoxytol. PeerJ 4: e2471, 2016.

16. Farr TD, Lai CH, Grünstein D, Orts-Gil G, Wang CC Boehm-Sturm P, Seeberger PH and Harms C: Imaging early endothelial inflammation following stroke by core shell silica superparamagnetic glyconanoparticles that target selectin. Nano Lett 14: 2130-2134, 2014.

17. Beckmann N, Cannet C, Babin AL, Blé FX, Zurbruegg S, Kneuer R and Dousset V: In vivo visualization of macrophage infiltration and activity in inflammation using magnetic resonance imaging. Wiley Interdiscip Rev Nanomed Nanobiotechnol 1 : 272-298, 2009.

18. Brochet B, Deloire MS, Touil T, Anne O, Caillé JM, Dousset V and Petry KG: Early macrophage MRI of inflammatory lesions predicts lesion severity and disease development in relapsing EAE. Neuroimage 32: 266-274, 2006

19. Marinescu M, Chauveau F, Durand A, Riou A, Cho TH Dencausse A, Ballet S, Nighoghossian N, Berthezène Y and Wiart M: Monitoring therapeutic effects in experimental stroke by serial USPIO-enhanced MRI. Eur Radiol 23: 37-47, 2013.

20. Luther EM, Petters C, Bulcke F, Kaltz A, Thiel K, Bickmeyer U and Dringen R: Endocytotic uptake of iron oxide nanoparticles by cultured brain microglial cells. Acta Biomater 9: 8454-8465, 2013.

21. Gkagkanasiou M, Ploussi A, Gazouli M and Efstathopoulos EP USPIO-Enhanced MRI Neuroimaging: A Review. J Neuroimaging 26: 161-168, 2016.

22. Strobel K, Hoerr V, Schmid F, Wachsmuth L, Löffler B and Faber C: Early detection of lung inflammation: Exploiting T1-effects of iron oxide particles using UTE MRI. Magn Reson Med 68: 1924-1931, 2012.

23. Belayev L, Alonso OF, Busto R, Zhao W and Ginsberg MD Middle cerebral artery occlusion in the rat by intraluminal suture. Neurological and pathological evaluation of an improved model. Stroke 27: 1616-1623, 1996.

24. Liu W, Wang X, Zheng Y, Shang G, Huang J, Tao J and Chen L: Electroacupuncture inhibits inflammatory injury by targeting the miR-9-mediated NF- $\kappa \mathrm{B}$ signaling pathway following ischemic stroke. Mol Med Rep 13: 1618-1626, 2016.
25. Sage JE, Samii VF, Abramson CJ, Green EM, Smith M and Dingus C: Comparison of conventional spin-echo and fast spin-echo magnetic resonance imaging in the canine brain. Vet Radiol Ultrasound 47: 249-253, 2006.

26. Attenberger UI, Runge VM, Stemmer A, Williams KD, Naul LG, Michaely HJ, Schoenberg SO, Reiser MF and Wintersperger BJ: Diffusion weighted imaging: A comprehensive evaluation of a fast spin echo DWI sequence with BLADE (PROPELLER) k-space sampling at 3T, using a 32-channel head coil in acute brain ischemia. Invest Radiol 44: 656-661, 2009.

27. Ohsawa K, Imai Y, Sasaki Y and Kohsaka S: Microglia/macrophage-specific Protein Ibal Binds to Fimbrin and Enhances Its Actin-bundling activity. J Neurochem 88: 844-856, 2004

28. Annovazzi L, Mellai M, Bovio E, Mazzetti S, Pollo B and Schiffer D: Microglia immunophenotyping in gliomas. Oncol Lett 15: 998-1006, 2018.

29. Konishi H, Kobayashi M, Kunisawa T, Imai K, Sayo A, Malissen B, Crocker PR, Sato K and Kiyama H: Siglec-H is a microglia-specific marker that discriminates microglia from CNS-associated macrophages and CNS-infiltrating monocytes. Glia 65: 1927-1943, 2017.

30. Castaneda RT, Khurana A, Khan R and Daldrup-Link HE: Labeling stem cells with ferumoxytol, an FDA-approved iron oxide nanoparticle. J Vis Exp: e3482, 2011.

31. Cui L, Hu J, Li CC, Wang CM and Zhang CY: An electrochemical biosensor based on the enhanced quasi-reversible redox signal of prussian blue generated by self-sacrificial label of iron metal-organic framework. Biosens Bioelectron 122: 168-174, 2018.

32. Ma Y, Ma L, Guo Q and Zhang S: Expression of bone morphogenetic protein-2 and its receptors in epithelial ovarian cancer and their influence on the prognosis of ovarian cancer patients. J Exp Clin Cancer Res 29: 85, 2010.

33. Anrather J and Iadecola C: Inflammation and stroke: An overview. Neurotherapeutics 13: 661-670, 2016.

34. Petrovic-Djergovic D, Goonewardena SN and Pinsky DJ: Inflammatory disequilibrium in stroke. Circ Res 119: 142-158, 2016.

35. Longa EZ, Weinstein PR, Carlson S and Cummins R: Reversible middle cerebral artery occlusion without craniectomy in rats. Stroke 20: 84-91, 1989.

36. Benedek A, Móricz K, Jurányi Z, Gigler G, Lévay G, Hársing LG Jr, Mátyus P, Szénási G and Albert M: Use of TTC staining for the evaluation of tissue injury in the early phases of reperfusion after focal cerebral ischemia in rats. Brain Res 1116: $159-165,2006$

37. Moraga A, Gómez-Vallejo V, Cuartero MI, Szczupak B, San Sebastián E, Markuerkiaga I, Pradillo JM, Higuchi M, Llop J, Moro MÁ, et al: Imaging the role of toll-like receptor 4 on cell proliferation and inflammation after cerebral ischemia by positron emission tomography. J Cereb Blood Flow Metab 36 : 702-708, 2016

38. Weinstein JS, Varallyay CG, Dosa E, Gahramanov S, Hamilton B, Rooney WD, Muldoon LL and Neuwelt EA: Superparamagnetic iron oxide nanoparticles: Diagnostic magnetic resonance imaging and potential therapeutic applications in neurooncology and central nervous system inflammatory pathologies, a review. J Cereb Blood Flow Metab 30: 15-35, 2010.

39. Shah A and Dobrovolskaia MA: Immunological effects of iron oxide nanoparticles and iron-based complex drug formulations: Therapeutic benefits, toxicity, mechanistic insights, and translational considerations. Nanomedicine 14: 977-990, 2018.

40. Weissleder R, Elizondo G, Wittenberg J, Rabito CA, Bengele HH and Josephson L: Ultrasmall superparamagnetic iron oxide: Characterization of a new class of contrast agents for MR imaging. Radiology 175: 489-493, 1990

41. Clemente-Casares X and Santamaria P: Nanomedicine in autoimmunity. Immunol Lett 158: 167-174, 2014.

42. Toyota T, Ohguri N, Maruyama K, Fujinami M, Saga T and Aoki I: Giant vesicles containing superparamagnetic iron oxide as biodegradable cell-tracking MRI probes. Anal Chem 84: 3952-3957, 2012.

43. Himmelreich U and Dresselaers T: Cell labeling and tracking for experimental models using magnetic resonance imaging. Methods 48: 112-124, 2009.

44. von Zur Muhlen C, von Elverfeldt D, Bassler N, Neudorfer I, Steitz B, Petri-Fink A, Hofmann H, Bode C and Peter K: Superparamagnetic iron oxide binding and uptake as imaged by magnetic resonance is mediated by the integrin receptor Mac-1 (CD11b/CD18): Implications on imaging of atherosclerotic plaques. Atherosclerosis 193: 102-111, 2007. 
45. Stoll G and Bendszus M: New approaches to neuroimaging of central nervous system inflammation. Curr Opin Neurol 23: 282-286, 2010

46. Yang YM, Feng X, Yin le K, Li CC, Jia J and Du ZG: Comparison of USPIO-enhanced MRI and Gd-DTPA enhancement during the subacute stage of focal cerebral ischemia in rats. Acta Radiol 55: 864-873, 2014

47. Nighoghossian N, Wiart M, Cakmak S, Berthezène Y, Derex L, Cho TH, Nemoz C, Chapuis F, Tisserand GL, Pialat JB, et al: Inflammatory response after ischemic stroke: A USPIO-enhanced MRI study in patients. Stroke 38: 303-307, 2007.

48. Balakrishnan VS, Rao M, Kausz AT, Brenner L, Pereira BJ, Frigo TB and Lewis JM: Physicochemical properties of ferumoxytol, a new intravenous iron preparation. Eur J Clin Invest 39: 489-496, 2009

49. Toth GB, Varallyay CG, Horvath A, Bashir MR, Choyke PL, Daldrup-Link HE, Dosa E, Finn JP, Gahramanov $S$ Harisinghani $\mathrm{M}$, et al: Current and potential imaging applications of ferumoxytol for magnetic resonance imaging. Kidney Int 92: 47-66, 2017.

50. Bashir MR, Bhatti L, Marin D and Nelson RC: Emerging applications for ferumoxytol as a contrast agent in MRI. J Magn Reson Imaging 41: 884-898, 2015.

51. Wiart M, Davoust N, Pialat JB, Desestret V, Moucharrafie S, Cho TH, Mutin M, Langlois JB, Beuf O, Honnorat J, et al: MRI monitoring of neuroinflammation in mouse focal ischemia. Stroke 38: 131-137, 2007.

52. Sekerdag E, Solaroglu I and Gursoy-Ozdemir Y: Cell death mechanisms in stroke and novel molecular and cellular treatment options. Curr Neuropharmacol 16: 1396-1415, 2018.

53. Kuschinsky W and Gillardon F: Apoptosis and cerebral ischemia. Cerebrovasc Dis 10: 165-169, 2000.

54. Müller K, Skepper JN, Posfai M, Trivedi R, Howarth S, Corot C, Lancelot E, Thompson PW, Brown AP and Gillard JH: Effect of ultrasmall superparamagnetic iron oxide nanoparticles (Ferumoxtran-10) on human monocyte-macrophages in vitro. Biomaterials 28: 1629-1642, 2007.

55. Hsiao JK, Chu HH, Wang YH, Lai CW, Chou PT, Hsieh ST, Wang JL and Liu HM: Macrophage physiological function after superparamagnetic iron oxide labeling. NMR Biomed 21 : 820-829, 2008

56. Siglienti I, Bendszus M, Kleinschnitz C and Stoll G: Cytokine profile of iron-laden macrophages: Implications for cellular magnetic resonance imaging. J Neuroimmunol 173: 166-173, 2006.

57. Oude Engberink RD, van der Pol SM, Döpp EA, de Vries HE and Blezer EL: Comparison of SPIO and USPIO for in vitro labeling of human monocytes: MR detection and cell function. Radiology 243: 467-474, 2007

58. Eamegdool SS, Weible MW II, Pham BT, Hawkett BS, Grieve SM and Chan-Ling T: Ultrasmall superparamagnetic iron oxide nanoparticle prelabelling of human neural precursor cells. Biomaterials 35: 5549-5564, 2014.

59. Doyle KP, Quach LN, Arceuil HE and Buckwalter MS Ferumoxytol administration does not alter infarct volume or the inflammatory response to stroke in mice. Neurosci Lett 584: 236-240, 2015.

60. Saleh A, Schroeter M, Ringelstein A, Hartung HP, Siebler M, Mödder U and Jander S: Iron oxide particle-enhanced MRI suggests variability of brain inflammation at early stages after ischemic stroke. Stroke 38: 2733-2737, 2007.
61. Wang Y, Wang B, Zhu MT, Li M, Wang HJ, Wang M, Ouyang H, Chai ZF, Feng WY and Zhao YL: Microglial activation, recruitment and phagocytosis as linked phenomena in ferric oxide nanoparticle exposure. Toxicol Lett 205: 26-37, 2011.

62. Pohland M, Glumm R, Wiekhorst F, Kiwit J and Glumm J: Biocompatibility of very small superparamagnetic iron oxide nanoparticles in murine organotypic hippocampal slice cultures and the role of microglia. Int $\mathbf{J}$ Nanomedicine 12: 1577-1591, 2017.

63. Christen T, Ni W, Qiu D, Schmiedeskamp H, Bammer R, Moseley $\mathrm{M}$ and Zaharchuk G: High-resolution cerebral blood volume imaging in humans using the blood pool contrast agent ferumoxytol. Magn Reson Med 70: 705-710, 2013.

64. Desestret V, Brisset JC, Moucharrafie S, Devillard E, Nataf S, Honnorat J, Nighoghossian N, Berthezène Y and Wiart M: Early-stage investigations of ultrasmall superparamagnetic iron oxide-induced signal change after permanent middle cerebral artery occlusion in mice. Stroke 40: 1834-1841, 2009.

65. van der Zijden JP, van der Toorn A, van der Marel K and Dijkhuizen RM: Longitudinal in vivo MRI of alterations in perilesional tissue after transient ischemic stroke in rats. Exp Neuro 212: 207-212, 2008.

66. Mishra SK, Kumar BS, Khushu S, Singh AK and Gangenahalli G: Early monitoring and quantitative evaluation of macrophage infiltration after experimental traumatic brain injury: A magnetic resonance imaging and flow cytometric analysis. Mol Cell Neurosci 78: 25-34, 2017.

67. Perego C, Fumagalli S and De Simoni MG: Temporal pattern of expression and colocalization of microglia/macrophage phenotype markers following brain ischemic injury in mice. J Neuroinflammation 8: 174, 2011.

68. Ortiz de Mendivil A, Alcalá-Galiano A, Ochoa M, Salvador E and Millán JM: Brainstem stroke: Anatomy, clinical and radiological findings. Semin Ultrasound CT MR 34: 131-141, 2013.

69. Nakamura $\mathrm{K}$ and Shichita T: Cellular and molecular mechanisms of sterile inflammation in ischaemic stroke. J Biochem 165: 459-464, 2019.

70. Hou K, Xu D, Li F, Chen S and Li Y: The progress of neuronal autophagy in cerebral ischemia stroke: Mechanisms, roles and research methods. J Neurol Sci 400: 72-82, 2019.

71. Haacke EM, Ayaz M, Khan A, Manova ES, Krishnamurthy B, Gollapalli L, Ciulla C, Kim I, Petersen F and Kirsch W: Establishing a baseline phase behavior in magnetic resonance imaging to determine normal vs. abnormal iron content in the brain. J Magn Reson Imaging 26: 256-264, 2007.

72. Schroeter M, Saleh A, Wiedermann D, Hoehn M and Jander S: Histochemical detection of ultrasmall superparamagnetic iron oxide (USPIO) contrast medium uptake in experimental brain ischemia. Magn Reson Med 52: 403-406, 2004.

This work is licensed under a Creative Commons Attribution-NonCommercial-NoDerivatives 4.0 International (CC BY-NC-ND 4.0) License. 